\title{
Effect of Washing with Acidified Water during Processing on the Quality of Spanish-Style Green Table Olive
}

\author{
Susan M. M. Abd-Elmageed \\ Oil and Fat Research Dept., Food Technology Research Institute, Agricultural Research Center, Giza, Egypt
}

Received: $3 / 2 / 2020$

\begin{abstract}
Table olives are one of the most consumed appetizers in the world. Egypt is currently the largest producer of table olives in the world. Manzanilla is the most valued table olive variety of preparation for Spanish-style green olive, in this technique, the olive fruits are sorted, graded by size and finally treated with a dilute $1.5 \%(\mathrm{w} / \mathrm{v})$ sodium hydroxide solution to remove bittemess (glucoside oleuropein). After this treatment, olives are washed with tap water several times at least 3 times to eliminate the excess of alkali. Washing waters of Spanish-style green olive processing are heavily contaminated waste streams that represent an important environmental problem that needs to be solved. The aim of this study was to evaluate the use of acidified water $\left(\mathrm{HCl} 1 \%\right.$ or $\left.\mathrm{H}_{2} \mathrm{SO}_{4} 1 \%\right)$ in washing of olive fruits treated with alkaline as well as the efficacy of this technique on the resultant fruits quality and sustainability of water used. The obtained results demonstrated that the possibility of olive fuits were washed after lye- treatment to only one time, by using acidified water with $\mathrm{HCl} 1 \%\left(\mathrm{WAW}_{\mathrm{HCl}}\right)$ or with $1 \% \mathrm{H}_{2} \mathrm{SO}_{4}\left(\mathrm{WAW}_{\mathrm{H} 2 \mathrm{SO}}\right)$ compared with fresh water (3 times), and the re-use of resultant wastewater after neutralization with $\mathrm{HCl} 7 \%$ as a safe water for irrigation. Oleuropein is responsible for bitterness, its content decreased during processing and fermentation in all treatments. Regarding sensory properties of olive pickles $\left(\mathrm{WAW}_{\mathrm{H} 2 \mathrm{SO} 4}\right)$ gave the lowest score of defects $0.5 \%$ meanwhile high score of smell (8) and taste (9). The study concluded obviously that the possibility to use acidified water $\left(\mathrm{H}_{2} \mathrm{SO}_{4} 1 \%\right)$ in olive fruits washing after lye-treatment without any changes in the olive pickles quality.
\end{abstract}

Keywords: Table olives, Manzanilla; Olea europaea L.; polyphenols, Spanish-style green olive; water saving

\section{INTRODUCTION}

Olive trees (Olea europaea L.) are a millenarian crop that was extended by Romans, Phoenicians and Arabs through the countries in the Mediterranean basin (Sánchez-Rodríguez et al., 2019). There are different olive varieties; some of them are used to extract olive oil and others for table olives because of their physical properties (volume, shape, firmness, etc.) (Cillidag, 2013). Table olives are one of the most consumed appetizers in the world; in fact, the global production of table olives for the 2019/20 crop year, showing a 13.9\% increase to 2,925,500 tons compared with 2,569,000 tons produced in the 2018/19 season (IOC, 2020). Egypt is the biggest producer of table olives in the world. In 2019, Egypt is the world's second largest producer of table olives and produced around 450,000 tons in $2018 / 19$ of which around 100,000 tons were exported. Egypt is expected to take the lead from Spain with a crop of 690,000 tons of olives compared with 497,000 last year (IOC, 2020).

Table olives composition is different from other fermented vegetables due to their high content of phenolic compounds and fatty acids, mainly oleic acid (monounsaturated), thus, it can be considered a functional food. Table olives' bioactivity can be influenced by many factors, such as cultivation technique and type of process to tum raw olives into table olives (Collado-González et al., 2015).

Table olives are well known sources of phenolic compounds, the major of which are hydroxytyrosol, elenolic acid, tyrosol and caffeic acid; their concentration is depended upon the ripening degree and the treatment method olive drupe till they became edible (Blekas et al., 2002; Charoenprasert and Michell, 2012). Bitterness in raw olives is usually attributed to the presence of oleuropein, which is the most prevalent phenolics present at harvest. Ripe olives contained high levels of bitter phenolic compounds including oleuropein and ligstroside that make the fruit inedible (Soler-rivas et al., 2000; Bianchi, 2003). However, oleuropein is not the only phenolic compound found in olives. Olive phenolics can be grouped into four broad categories: phenolic acids, phenolic alcohols, flavonoids, and secoiridoids (Charoenprasert and Mitchell, 2012). Also, the phenolic compounds contributed to sensory characteristics of olive products, further to their pharmaceutical and physiological benefits (Covas et al., 2006).

'Manzanilla' is the most valued table olive variety because of its high productivity and its good fruit quality. In Egypt, it is typical to harvest olives when they are green to process them following the Spain-style. 'Manzanilla' olives have medium aptitude for oil extraction whereas its oil has good quality and stability; therefore, this variety is perfect to be processed to table olives (ASEMESA, 2018). 'Manzanilla' olives have a thin peel and the flesh is delicate, hard, pulpy, tasty, and non-fibrous (Cano-Lamadrid et al., 2015). Furthermore, the removal of the flesh from the pit is very easy (ASEMESA, 2018); this characteristic is important for the industry because it makes the pitting process easier (IOC, 2004).

Raw olives are firm and bitter, so some processes are necessary to make them edible. Each method of debittering produced a different style of table olives with a unique texture and chemical, microbial, and sensorial profiles, general, any processing method aims to remove the natural bittemess of this fruit, caused by the glucoside oleuropein and as a result, can alter the 
health-promoting potential of various table olive products (Blekas et al., 2002; Melliou et al., 2015).

Table olives can be processed using different techniques, and the Spanish-style green table olive process is the most common in Egypt. It consists of: (i) treatment of debittering (lye treatment) to hydrolyze oleuropein, (ii) washing process, to remove alkali, and (iii) lactic acid fermentation (Cortés-Delgado et al., 2016). During alkali treatment, some components, such as tocopherol and free fatty acids, diffuse from the olive peel to the surrounding liquid; this process increases the cellular membrane permeability and contributes to decreased peel firmness (Mojtaba et al., 2015).

The Spanish processing method included lye treatment, for the total removal of the bitter compound oleuropein (generating hydroxytyrosol and elenolic acid glycoside), washing, brining and fermentation, sorting and packaging (Romero et al., 2004). Additionally, current commercial table olive processing methods are some of the most water intensive methods used in commercial food processing and can require more than 7,571 liters of water per ton of olives (e.g., Spanish method) and generate highly toxic wastewater. Throughout, in all stages of lye treatment, large quantities of clean water are used and was tewaters about 3.9-7.5 $\mathrm{m}^{3} / \mathrm{t}$ of olives (Abou-Zaid and Ibraheeem, 2015). The washing solutions are heavily contaminated and contain a high content of sugars and phenolic compounds, particularly hydroxytyrosol (3,4dihydroxyphenyl ethanol) (De Castro and Brenes, 2001).

Increased consumer demand for healthier food products that are produced in an environmentally sustainable manner, as well as industrial interest in decreasing processing time, water usage, and cost, demonstrates the need for innovation in olive process in technologies (Johnson and Mitchell, 2018). Spanish processing method of green olives produce about 3.5liter wastewater per $\mathrm{Kg}$ olive $(0.5 \mathrm{~L}$ for lye treatment, 2$2.5 \mathrm{~L}$ for washing 3 times and $0.5 \mathrm{~L}$ for fermentation, so the aim of this study was to reduce the quantity of washing water of Spanish-style processing from 3 times to only ones by using acidified water $\left(\mathrm{HCl} 1 \%\right.$ or $\mathrm{H}_{2} \mathrm{SO}_{4}$ $1 \%$ ) in washing of olive fruits treated with alkaline as well as the efficacy this technique on the resultant fruits quality and sustainability of water used.

\section{MATERIALS AND METHODS}

\section{Materials:}

Manzanilla olives were obtained from a desert Road farm at Wadi El-Natrun, Beheira Governorate, Egypt. Table (1) showed some characters of Manzanilla olive used in this study. Standard fatty acid and all chemicals used were of analytical grade and obtained from Sigma-Aldrich Chemical Co. England. Sodium hydroxide, $\mathrm{NaCl}$, acetic acid and lactic acid were obtained from local market, Cairo Governorate, Egypt.
Table (1): Some characters of raw Manzanilla olive fruits used in Spanish-style process

\begin{tabular}{lc}
\hline Items & Manzanilla olive \\
\hline Weight of 100 unit $(\mathrm{g})$ & 605 \\
Flesh: stone & $3.6: 1$ \\
Number of unit/Kg & 180 \\
Color & Green \\
\hline
\end{tabular}

\section{Methods :}

Experimental design:

The experiment was carried out with Manzanilla olive fruits (Olea europaea Ponifarmis). The olive fruits must be fresh, firm to the touch, not shriveled and free of any marks due to insect bites or sting.

The experiment was carried out with Manzanilla fruit using Spanish-style process. It consisted of treating $30 \mathrm{Kg}$ with $20 \mathrm{~L}$ lye solution $(1.5 \mathrm{~g} \mathrm{NaOH} / 100 \mathrm{ml})$ until this reached $2 / 3$ of the flesh (6h) followed by washing to remove the excess of alkali. The end of the washing process can be tested by using a few drops of the phenolphthalein indicator.

Thirty $\mathrm{Kg}$ were divided into three portions:

1. $10 \mathrm{Kg}$ were washed with fresh water 3 times (control).

2. $10 \mathrm{Kg}$ were washed with acidified water with $\mathrm{HCl}$ $1 \%$. $\left(\mathrm{WAW}_{\mathrm{HCl}}\right)$

3. $10 \mathrm{Kg}$ were washed with acidified water with $\mathrm{H}_{2} \mathrm{SO}_{4} 1.0 \%$. (WAW $\mathrm{H}_{2 \mathrm{SO}}$ )

The debittered olives were then brined with $10 \%$ $\mathrm{NaCl}$ solution. The total acid expressed as lactic acid content of the brine should be $0.3 \%$ for fermentation. Olive samples were taken after 3 months of fermentation for analy ses.

\section{Analyses \\ Physical and chemical analyses:}

The average weights of samples were determined by meas uring the weights of 30 olive fruits and their pits were removed and weighted. Some of the chemical and physical properties (moisture, color, fruit and pit weight) of the olives were analyzed according to AOAC (2005). Proximate composition (mois ture, crude protein, crude oil, crude fiber, total sugars and ash) were determined for the prepared Manzanilla table olive fruits according to Official Methods (AOAC, 2005). Also, $\mathrm{pH}$ of olives fruits was determined according to AOAC (2005).

\section{Phenolic compounds \\ Preparation of extracts}

For polyphenols measurement, all samples were previously treated in order to extract them according to the method described by McDonald et al. (2001) with slight modifications. Five grams of dried olives were mixed with $25 \mathrm{ml}$ of methanol and centrifuged at 3000 $\mathrm{rpm} / 5 \mathrm{~min}$ (Sigma 2-16 K, Germany). The residue was extracted again in the same conditions, and the extracts were combined then filtered. 


\section{Total polyphenols compounds and its profile}

The total polyphenols content of the methanolic extracts was determined with Folin-Ciocalteu reagent as described by Malik and Bradford (2006). Total polyphenols values were expressed as gallic acid equivalents (GAE, $\mathrm{mg} / 100 \mathrm{~g}$ dry weight) from a calibration curve $\left(y=0,0036 x ; R^{2}=0.99\right)$. Qualitative analys is of phenols and phenolic acids was performed with gas chromatography/mass spectrometry according to Boskou et al.(2006).

\section{Oil extraction}

Dried Manzanilla olive fruits were ground in a laboratory mill and soaked in $\mathrm{n}$-hexane for $24 \mathrm{~h}$ twice. Solvent was collected and evaporated under vacuum. The produced oils were filtered and kept in dark bottles in the refrigerator untilused.

\section{Gas chromatography analysis for fatty acids Methylation of fatty acids}

An aliquot of oils, about $10 \mathrm{mg}$, was dissolved in hexane and then $0.4 \mathrm{ml} 2 \mathrm{~N} \mathrm{KOH}$ in anhydrous methanol was added (Cossignani et al., 2005), after 3 $\mathrm{min}, 3 \mathrm{ml}$ water was added. The organic layer was separated, dried over anhydrous sodium sulfate, and then concentrated with a $\mathrm{N}_{2}$ stream to around $0.5 \mathrm{ml}$ for GC analysis of fatty acids methyl esters (FAMF) as described below.

\section{Identification of fatty acids methyl esters by GC}

Agilent 6890 series GC apparatus provided with a DB-23 column (30 m x $0.32 \mathrm{~nm} \times 0.25 \mu \mathrm{m}$ ). Fatty acids methyl esters directly injected into the GC. Carrier gas was $\mathrm{N}_{2}$ with a flow rate of $2 \mathrm{ml} / \mathrm{min}$, splitting ratio of 1:100. The injector temperature was $250^{\circ} \mathrm{C}$ and that of FID detector was $270^{\circ} \mathrm{C}$. The temperature settings were as follows: 150 to $225^{\circ} \mathrm{C}$ at $5^{\circ} \mathrm{c} / \mathrm{min}$, and then held at $225^{\circ} \mathrm{C}$ for $20 \mathrm{~min}$. peak identification was performed by comparison of the retention time (RT) for each peak with those of standard fatty acids. The peaks areas were measured using the Chemstation Program, and relative areas of the identified fatty acids were recorded.

\section{Sensory evaluation}

The consumer test was based on the gustatory (acid, salty and bitter) and kinesthetic sensations (hardness, fibrousness and crispness) of the evaluation sheet for the Methods of sensory analys is of table olives (IOC, 2010). The panelists were 8 experienced judges of Oil and Fat Research Dept., Food Technology Research Institute, Agricultural Research Center, habitual consumers of olives with a high level of training due to their participation for decades in the development of the method for the sensory analysis of table olives.

\section{RESULTS AND DISCUSSIONS}

\section{Chemical evaluation of olives}

The chemical composition of fresh olive fruit of Manzanilla and the changes in the chemical composition of Spanish-style green table olive (control, $\mathrm{WAW}_{\mathrm{HCl}}$ and $\mathrm{H}_{2} \mathrm{SO}_{4}$ ) during processing are presented in Table (2). The proximate composition of fresh Manzanilla olive fruit were $63.32,15.73,7.87,5.35,3.98$ and $3.75 \%$ for mois ture, lipid, fiber, sugar, as $h$ and protein, respectively.

The moisture content of pickled Manzanilla olives recorded the highest moisture content compared to fresh olive fruits. The moisture content of the final product considered an important parameter related to firmness and other sensory properties. The increase in moisture contents could be attributed to the decrease in total soluble solids during the fermentation period (AbouZaid and Ibraheem, 2015).

Data in Table (2) revealed that the chemical composition of Spanish-style Manzanilla olive, all studied treatments led to a decrease in total fat. From the same table, it could be noticed that, the highest loss of crude fat was recorded for lye treatment followed by washing acidified water with $\mathrm{HCl}$ or $\mathrm{H}_{2} \mathrm{SO}_{4}$, this may be due to the effect of these treatment on the permeability of cell wall of olive fruits leading that to lipids loss in soaking and brine solutions. These results agreed with the results previously reported by Abou-Zaid and Ibraheem(2015).

Table (2): Effect of different treatments on chemical composition of Manzanilla olive fruits (\%)

\begin{tabular}{lcccc}
\hline & Fresh olive & \multicolumn{3}{c}{ Treatments } \\
\cline { 3 - 5 } Proximate composition & & Control & WAW & WAW $_{\text {H2SO4 }}$ \\
\hline Moisture (\%) & 63.32 & 64.25 & 65.32 & 67.14 \\
Crude oil (\%) & 15.73 & 14.84 & 14.79 & 14.22 \\
Crude protein (\%) & 3.75 & 5.21 & 5.03 & 3.93 \\
Total sugar(\%) & 5.35 & $\mathrm{ND}$ & $\mathrm{ND}$ & $\mathrm{ND}$ \\
Ash (\%) & 3.98 & 6.06 & 5.99 & 4.89 \\
Crude fiber $(\%)$ & 7.87 & 9.64 & 8.87 & 9.82 \\
$\begin{array}{l}\text { Total polyphenols content } \\
\text { (mg/100) }\end{array}$ & 604 & 375 & 240 & 235
\end{tabular}

Fresh olives: fresh Manzanilla olives; ND: not detected

Control: Final product of Spanish-style Manzanilla olives, after 3 months' fermentation washed 3 times with fresh water

WAW $\mathrm{HCl}$ : Final product of Spanish-style Manzanilla olives, after 3 months' fermentation washed one time with acidified water HCl $1.0 \%$

WAW H2sO4: Final product of Spanish-style Manzanilla olives, after 3 months' fermentation washed one time with acidified water $\mathrm{H}_{2} \mathrm{SO}_{4}$ 1.0\% 
Total sugar of fresh olive was $5.35 \%$, however when the olives are washed or lye treated and fermented, sugars are also completely lost or consumed along with other soluble compounds or by microorganisms. These results are in agreement with that reported by Hurtado et al. (2008) and Cardoso et al. (2010). The mentioned data in Table (2) indicated obviously that, all studied treatments had a positive effect on polyphenol removing comparing to the traditional treatment (control) either for olive fruits after treatments (WAW $\mathrm{HCl}$ or $\mathrm{H} 2 \mathrm{SO} 4$ ), where the maximum removing rate was recorded for $\mathrm{WAW}_{\mathrm{H} 2 \mathrm{SO} 4}$ (235 $\mathrm{g} / 100 \mathrm{~g}$ ), while the minimum removing rate was recorded for traditional treatment (control) (375 $\mathrm{mg} / 100 \mathrm{~g}$ ). These results are in harmony with those of Abou-Zaid and Ibraheem(2015).

\section{Changes of fatty acids during processing}

Fatty acid composition of olive oil extracted from Manzanilla olive, WAW $\mathrm{HCl}_{\mathrm{HC}}$ and $\mathrm{WAW}_{\mathrm{H} 2 \mathrm{SO} 4}$ compared with control after 3 months of fermentation and fresh olive are represented in Table (3). There are some variations in the fatty acid composition of $\mathrm{WAW}_{\mathrm{HCl}}$, WAW $\mathrm{H}_{2 \mathrm{SO}}$ and control compared with fresh olive were observed.
As shown in Table (3), palmitic, oleic acid and linoleic acid in all samples were found as major fatty acids. The levels of oleic acid were 76.60, 74.47, 71.98 and 71.66 and linoleic acid were 10.34, 9.12, 11.17 and 10.33 and palmitic acid were 8.82, 9.93, 10.97 and 11.05 for fresh olive, control, $\mathrm{WAW}_{\mathrm{HCl}}$ and WAW $\mathrm{H}_{2 \mathrm{SO}}$ respectively. Oleic acid content decreases during processing and fermentation of $\mathrm{WAW}_{\mathrm{HCl}}(6.03 \%)$ and WAW ${ }_{\text {H2SO4 }}(6.44 \%)$ compared with control $(2.78 \%)$. The results also showed that total saturated fatty acids content tend to increase (29-44\%), while total unsaturated fatty acids tends to decrease of WAW $\mathrm{HCl}$ $(4.48 \%)$ and WAW H2SO4 $(5.73 \%)$ compared with control $(3.85 \%)$, may be due to that unsaturated fatty acids high affected with $\mathrm{NaOH}$ during processing and saturated fatty acids more stable. The level of saturated fatty acids of control $(29.63 \%), \mathrm{WAW}_{\mathrm{HCl}}(34.4 \%)$ and WAW ${ }_{\text {H2SO4 }}(44.05 \%)$ olive samples increased during processing and fermentation compared with fresh olive. Also, the ratio between saturated and unsaturated fatty acids in all samples was increased (30-72\%) during processing and fermentation. The results are in agreement with that reported by Salas et al. (2000).

Table (3): Fatty acid profile (\%)

\begin{tabular}{|c|c|c|c|c|}
\hline \multirow{2}{*}{ Fatty acid } & \multirow{2}{*}{ Fresh olive } & \multicolumn{3}{|c|}{ Treatments } \\
\hline & & Control & WAW $_{\mathrm{HCl}}$ & WAW $_{\mathrm{H} 2 \mathrm{SO} 4}$ \\
\hline Palmitic $\mathrm{C}_{16: 0}$ & 8.82 & 9.93 & 10.97 & 11.05 \\
\hline Palmitoleic $\mathrm{C}_{16: 1}$ & 0.73 & 0.71 & 0.69 & 0.67 \\
\hline Stearic $\mathrm{C}_{18: 0}$ & 2.64 & 4.99 & 4.48 & 5.53 \\
\hline Oleic $\mathrm{C}_{18: 1}$ & 76.60 & 74.47 & 71.98 & 71.66 \\
\hline Linoleic $\mathbf{C}_{18: 2}$ & 10.34 & 9.12 & 11.17 & 10.33 \\
\hline Linolenic $\mathrm{C}_{18: 3}$ & 0.82 & 0.78 & 0.69 & 0.76 \\
\hline Arachidic $\mathrm{C}_{20: 0}$ & 0.05 & $\mathrm{ND} *$ & 0.02 & ND \\
\hline Total saturatedfatty acid & 11.51 & 14.92 & 15.47 & 16.58 \\
\hline Total unsaturatedfatty acid & 88.49 & 85.08 & 84.53 & 83.42 \\
\hline Monounsaturated fatty acid & 77.33 & 75.18 & 72.67 & 72.33 \\
\hline Polyunsaturated fatty acid & 11.16 & 9.9 & 11.86 & 11.09 \\
\hline $\begin{array}{l}\text { Total saturated/total unsaturated } \\
\text { fatty acid }\end{array}$ & 0.13 & 0.17 & 0.18 & 0.19 \\
\hline
\end{tabular}

Fresh olives: fresh Manzanilla olives; ND: not detected

Control: Final product of Spanish-style Manzanilla olive after 3 months of fermentation washed 3 times with fresh water

$\mathrm{WAW}_{\mathrm{HCl}}$ : Final product of Spanish-style Manzanilla olive after 3 months of fermentation washed one time with acidified water $\mathrm{HCl} 1.0 \%$

$\mathrm{WAW}_{\mathrm{H} 2 \mathrm{SO}}$ : Final product of Spanish-style Manzanilla olive after 3 months of fermentation washed one time with acidified water $\mathrm{H}_{2} \mathrm{SO}_{4} 1_{1.0 \%}$

\section{Changes of phenolic compounds}

Oleuropein and related bitter phenolics can be reduced in table olives through several different mechanisms. Strong acids or bases can penetrate the olive flesh directly, where free $\mathrm{H}^{+}$and $\mathrm{OH}^{-}$ions catalyze the hydrolysis of oleuropein at the ester group that connects the hydroxytyrosol/tyrosol to the elenolic acid moiety. This hydrolys is reaction produced the non- bitter hydrolysis products oleoside methyl ester and hydroxytyrosol/tyrosol(Soler-rivas et al., 2000).

During brine-based processing, bitter phenolics are removed from the olive by diffusing from the fruit into surrounding brine. Once these compounds have diffused into the brine, the acid and/or the enzymatic action of exogenous enzymes, $\beta$-glucosidase, and esterase from the microbiota present in the brine or surface of the 
olive can hydrolyze the phenolic compounds (Medina et al., 2017). While phenolic compounds diffuse out of the olive, salt and acid from the brine diffuse in, changing the chemical and sensory profile of the product (Maldonado et al., 2008). If the cellular structure of the olive is compromised, either by chemical (e.g., lye), physical (e.g., cracking, slitting, or destoning), or the natural biochemical softening, diffusion can occur more rapidly.
The polyphenols profile and content of resultant Manzanillo olive fruits were tabulated in Table (4). The obtained results demonstrated obviously that, all washing with acidified water treatments had noticeable effects on polyphenol removal than control. The main phenolic components found in fresh Manzanillo olive were oleuropein, hydroxytyrosol, hydroxyphenyl acetic acid and tyrosol (Table 4).

Table (4): Poly phenols profile and content $(\mathrm{mg} / \mathrm{kg})$ in fres h Manzanilla olive, control, W AW $\mathrm{HCl}$ and WAW $\mathrm{H} 2 \mathrm{SO} 4(\mathrm{mg} / \mathrm{kg})$

\begin{tabular}{|c|c|c|c|c|}
\hline \multirow{2}{*}{ Phenolic compounds } & \multirow{2}{*}{ Fresh olive } & \multicolumn{3}{|c|}{ Treatments } \\
\hline & & Control & $\mathbf{W A W}_{\mathrm{HCl}}$ & WAW $_{\mathrm{H} 2 \mathrm{SO} 4}$ \\
\hline \multicolumn{5}{|c|}{ Phenolic acids } \\
\hline Cinnamic acid & 0.35 & 0.18 & 0.14 & 0.16 \\
\hline Hydroxyphenyl acetic acid & 24.72 & 19.93 & 20.42 & 19.06 \\
\hline Hydroxybenzoic acid & 5.64 & 3.25 & 4.33 & 3.80 \\
\hline Caffeic acid & 0.47 & 0.41 & 0.38 & 0.33 \\
\hline Coumaric acid & 2.16 & 1.48 & 0.95 & 1.82 \\
\hline Vanillic acid & 3.87 & 1.90 & 1.85 & 2.03 \\
\hline Syringic acid & 0.49 & 0.22 & 0.41 & 0.28 \\
\hline \multicolumn{5}{|c|}{ Phenolic alcohol } \\
\hline Hydroxytyros ol & 46.88 & 41.30 & 42.11 & 43.39 \\
\hline Tyrosol & 18.23 & 14.68 & 14.96 & 15.23 \\
\hline \multicolumn{5}{|c|}{ Flavonoids } \\
\hline Taxifolin & 0.51 & 0.47 & 0.33 & 0.47 \\
\hline Apigenin & 2.14 & 1.96 & 2.00 & 1.79 \\
\hline \multicolumn{5}{|c|}{ Secoiridoids } \\
\hline Oleuropein & 72.55 & 13.15 & 10.22 & 13.41 \\
\hline Verbascoside & 1.28 & 0.85 & 1.16 & 0.78 \\
\hline
\end{tabular}

Fresh olives: fresh Manzanilla olives

Control: Final product of Spanish-style Manzanilla olive after 3 months of fermentation washed 3 times with fresh water

W AW $_{\mathrm{HCl}}$ : Final product of Spanish-style Manzanilla olive after 3 months of fermentation washed one time with acidified water $\mathrm{HCl} 1.0 \%$

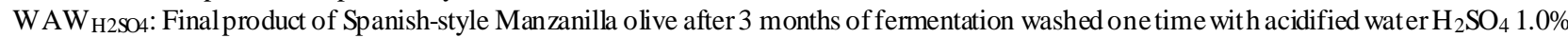

Also, the results in Table 4 showed that amount of all phenolic compounds decreased during processing and after fermentation in control, $\mathrm{WAW}_{\mathrm{HCl}}$ and $\mathrm{WAW}_{\mathrm{H} 2 \mathrm{SO} 4}$, concurred with the results obtained by Gomez-Rico et al. (2008) reported that oleuropein showed the highest level among the others phenolics and decreased during processing but the content of oleuropein was high affected during processing and fermentation in all samples. These results in harmony with those of Servilli et al. (2006), the phenolic compounds undergo during olive processing mainly, the alkaline hydrolys is and/or the microbial degradation of oleuropein into hydroxytyrosol and elenolic acid glucoside during debittering and brining process. Meanwhile, the content of hydroxyphenyl acetic acid, tyrosol and hydroxytyrosol were less affected during processing and fermentation (Abou-Zaid and Ibraheem, 2015).

\section{Organoleptic characteristic}

The sensory profile technique was used to study the sensory attributes which best characterize the three processing styles of Manzanilla olive. Sensory evaluation of Spanish-style green Manzanilla olives (control, WAW $\mathrm{HCl}$ and $\mathrm{WAW}_{\mathrm{H} 2 \mathrm{SO} 4}$ ) was invested after processing and 3 months of fermentation process. The obtained results are tabulated in Table (5). The results showed that treated $\left(\mathrm{WAW}_{\mathrm{H} 2 \mathrm{SO}}\right)$ gave the lowest score of defects $0.5 \%$ meanwhile exhibited a high score of smell and taste 8 and 9 . But, control gave high score of defect $2 \%$ and high score of smell and taste 8 and 9 followed by $\mathrm{WAW}_{\mathrm{HCl}}$ gave $1.5 \%$ defect and 8 and 7 score of smell and taste. These results in harmony with those of Maria et al. (2010) reported that sensory evaluation led to the conclusion that a revision of technological procedures may improve the final quality of product. The results of three treated samples showed that good quality of hardness, texture and crispness while salty and acid tastes give medium score. The best debittering conditions was the olives washed with acidified water with $\mathrm{H}_{2} \mathrm{SO}_{4}$ gave the lowest score of bitterness and defect 2 and $0.5 \%$ and a high score of smell and taste. The results are in agreement with that reported by Maria et al. (2010). 
Table (5): Sens ory evaluation of the resultant Spanish-sty le Manzanilla olives

\begin{tabular}{lccc}
\hline \multirow{2}{*}{ Sensory attributes } & \multicolumn{3}{c}{ Treatments } \\
\cline { 2 - 4 } Acid & Control & WAW & WAW $_{\text {H2SO4 }}$ \\
Salty & 4.5 & 5 & 3.5 \\
Bitter & 5.0 & 6 & 5 \\
Hardness & 3 & 2.5 & 2 \\
Crispness & 7 & 6.5 & 7 \\
Fibrousness & 7 & 6.5 & 7.5 \\
Smell & 6.50 & 7.5 & 8.5 \\
Taste & 9 & 8 & 9 \\
Color & 8 & 7 & 8 \\
Defect $(\%)$ & Yellowish green & Yellowish green & Yellowish green \\
\hline
\end{tabular}

Control: Final product of Spanish-style Manzanilla olive after 3 months of fermentation washed 3 times with fresh water

WAW $_{\mathrm{HCl}}$ : Final product of Spanish-style Manzanilla olive after 3 months of fermentation washed one time with acidified water $\mathrm{HCl} 1.0 \%$ $\mathrm{WAW}_{\mathrm{H} 2 \mathrm{SO}}$ : Final product of Spanish-style Manzanilla olive after 3 months of fermentation washed one time with acidified water $\mathrm{H}_{2} \mathrm{SO}_{4} 1.0 \%$

\section{Changes in $\mathrm{pH}$ value during fermentation of treated Manzanilla olive}

After washing with fresh water and acidified water to eliminate the residual alkali (lye), olives are covered with sodium chloride solution $10 \%$ (brine) and left to develop lactic fermentation. Initial brine concentration is $10 \% \mathrm{NaCl}$ but rapidly declines to $6 \%$ due to the high content of interchangeable water in the olive. Fermentation starts as soon as the olives are placed in brine. After alkaline treatment, the $\mathrm{pH}$ values of olives were $12.1,11.5$ and 11.2 for control, WAW $\mathrm{HCl}$ and $\mathrm{WAW}_{\mathrm{H} 2 \mathrm{SO} 4}$, respectively, down to the value of $8.2,7.8$ and 7.5 after washing. After 10 days' fermentation, the $\mathrm{pH}$ values of olives were $6.3,5.5$ and 5.2, it continued to decline the value of $4.8,4.5$ and 4.5 . This low $\mathrm{pH}$ promoted the growth of lactic acid bacteria. At the end of lactic fermentation, the $\mathrm{pH}$ reached 3.6, 3.6 and 3.5 for control, $\mathrm{WAW}_{\mathrm{HCl}}$ and $\mathrm{WAW}_{\mathrm{H} 2 \mathrm{SO} 4}$, res pectively.
The results are in agreement with that reported by Sanchez et al. (2001) which mentioned that lactic acid bacteria started fermentation immediately after washing at $\mathrm{pH}$ 9. In this case obviously, the strain used as starter is not necessarily eleuropeinolytic because lye has just demolished the bitter glucoside. The importance of this type of starter is to reduce the log phase and spoilage.

Spanish processing method of green olives produce about 3.5-liter wastewater per $\mathrm{Kg}$ olive $(0.5 \mathrm{~L}$ for lye treatment, 2-2.5 L for washing 3 times and $0.5 \mathrm{~L}$ for fermentation, so the aim of this study was to reduce the quantity of washing water of Spanish style processing from 3 times to only ones by using acidified washing water. Also, neutralizing the alkalinity of wastewater tends to produce safe water which can be utilized.

Table (6): Changes in pHvalue during fermentation of treated Manzanilla olive

\begin{tabular}{lccc}
\hline Time of determination & Control & WAW $_{\mathbf{H C l}}$ & WAW $_{\mathbf{H} 2 \mathrm{SO}}$ \\
\hline After alkali treatment & 12.1 & 11.5 & 11.2 \\
After washing & 8.1 & 7.8 & 7.5 \\
After 10 day of fermentation & 6.3 & 5.5 & 5.2 \\
After 30 day of fermentation & 4.8 & 4.5 & 4.5 \\
After 45 day of fermentation & 4.1 & 3.8 & 3.9 \\
After 60 day of fermentation & 3.8 & 3.6 & 3.6 \\
At the end of lactic fermentation & 3.6 & 3.6 & 3.5 \\
\hline
\end{tabular}

Control: Final product of Spanish-style Manzanilla olive after 3 months of fermentation washed 3 times with fresh water 


\section{CONCLUSION}

Increased consumer demand for healthier food products as well as high quality products that are produced in an environmentally sustainable manner, as well as industrial interest in decreas ing processing time, water usage, and cost, demonstrates the need for innovation in olive processing technologies. Regarding, the effect of washing of Spanish-style green table olive by acidified water was not affected on the quality of olive during processing and after fermentation. The washing acidified water with acids $\left(\mathrm{HCl}, \mathrm{H}_{2} \mathrm{SO}_{4}\right)$ decreasing processing time, decreasing water usage, improving sustainability, increasing the health properties of processed fruit, and decreas ing production cost. The quantity of washing water of Spanish-style processing reduced from 3 times to only ones by using acidified washing water. Also, neutralizing the alkalinity of wastewater tends to produce safe water which can be utilized.

\section{REFERENCES}

Abou-Zaid, F. O. F. and A. A. Ibraheem (2015). Using of some different acids in de-bittering of green olives. J. Food and Dairy Sci., Mansoura Univ., 6(5): 393-404.

AOAC (2005). Official Methods of Analys is, $14^{\text {th }}$ edition Association of Official Agricultural Chemists Official Methods of Analysis. Washington DC. USA.

ASEMESA (2018). Spanish Association of Producers and Exporters of Table Olives. (2018). http://www.asemesa.es/core_media/asemesa/La \%20 aceituna/Manzanilla\%20de\%20Sevilla.pdf [January 2018].

Bianchi, G. (2003). Lipids and phenols in table olives. European Journal of Lipid Science and Technology, 105: 229-242.

Blekas, G., C. Vassilakis, C. Harizanis, M. Tsimidou and D. G. Boskou (2002). Biophenols in table olives. J. Agric. Food Chem., 50: 3688 3692.

Boskou, G., F. N. Salta, S. Chrysostomou, A. Mylona, A. Chiou and N. K. Andrikopoulos (2006). Antioxidant capacity and phenolic profile of table olives from the Greek market. Food Chem., 94(4): 558-564.

Cano-Lamadrid, M., I. F. Girón, R. Pleite, F. Burló, M. Corell and A. Moriana (2015). Quality attributes of table olives as affected by regulated deficit irrigation. LWT-Food Sci. Technol., 62: 19-26.

Cardoso, S. M., I. Mafra, A. Reis, C. Nunes, J. A. Saraiva and M. A. Coimbra (2010). Naturally fermented black olives: Effect on cell wall polysaccharides and on enzyme activities of Taggiasca and Conservolea varieties. Food Science and Technology, 43: 153-160.

Charoenprasert, S. and A. Mitchell (2012). Factors influencing phenolic compounds in table olives (Olea europaea). Journal of Agricultural and Food Chemistry, 60(29): 7081-7095.
Cillidag, S. I. (2013). Table olive processing technologies. Options Mediterraneennes, A, 106: 67-74.

Collado-González, J., A. Moriana, I. F. Girón, M. Corell, S. Medina and T. Durand (2015). The phyto protein content in green table olives is influenced by Spanish-style processing and regulated deficit irrigation. LWT-Food Sci. Technol., 64: 997-1003.

Cortés-Delgado, A., A. H. Sánchez, A. de Castro, A. López-López, V. M. Beato and A. Montaño (2016). Volatile profile of Spanish-style green table olives prepared from different cultivars grown at different locations. Food Res. Int., 83: 131-142.

Cossignani, L., M. S. Simonetti and P. Damiani (2005). Biocatalyze dacidolysis of olive triacylglyceols with $9 \mathrm{c}, 11 \mathrm{t}$ and $10 \mathrm{t}, 12 \mathrm{c}$ is omers of conjugated linoleic acid. Eur. Food Res. Techol., 220: 267271.

Covas, M., K. Nyyssonen and H. Poulsen (2006). The effect of polyphenols in olive oil on heart disease risk factors. In: Ann. Int. Med., 145: 333-431.

De Castro, A. and M. Brenes (2001). Fermentation of washing waters of Spanish-style green olive processing. Process Biochemistry, 36: 797-802.

Gomez-Rico, A., G. Fregapane and M. D. Salvador (2008). Effect of cultivar and ripening on minor component in Spanish olive fruits and their corresponding virgin olive oils. Food Res. Int., 41: 433-440.

Hurtado, A., C. Reguant, E. Esteve-Zarzoso, A. Bordons and N. Rozes (2008). Microbial population dynamics during the processing of Arbequina table olives. Food Research Intemational, 41: 738-744.

IOC (2004). Trade Standard Applying to Table Olives. (Intemational Olive Council), 1 December 2004., Madrid: IOC

IOC (2010). Sensory Analysis of Table Olives. International Olive Council, COI/OT/N ${ }^{0} \mathrm{I} / \mathrm{Rev} \mathrm{I}$ February 2010. Madrid: IOC.

IOC (International Olive Council) (2020). Council Releases Estimates for 2019/20 Table Olive Production., 4Feb. 2020.

Johnson, R. L. and A. E. Mitchell (2018). Reducing Phenolics Related to Bitterness in Table Olives. Joumal of Food Quality, 2018, Article ID $3193185, \quad 12 \quad$ pages. https://doi.org/10.1155/2018/3193185

Maldonado, M. B., C. Zuritz and M. V. Assof (2008). Diffusion of glucose and sodium chloride in green olives during curing asaffected by lye treatment. J. Food Eng., 84(2): 224-230.

Malik, N. S. and J. M. Bradford (2006). Changes in Oleuropein olives during differentiation and development of floral buds in Arbequina olives. Sci. Hortic., 110: 274-278.

Maria, A., V. Valeria, B. Giuseppe, V. Giorgio, F. Vittorio, A. Giuseppe, M. Carmela and M. Giancarlo (2010). Study of green Sicilian table olive fermentation through microbiological, 
chemical and sensory analyses. Food Microbiology, 27: 162-170.

McDonald, S., P. D. Prenzler, M. Antolovich and K. Robards (2001). Biochemical studies on plantago major L. Farmacognosia-5-passei Direto. Food Chem., 73: 73-84.

Medina, E., E. Ramírez, M. Brenes and A. Castro (2017). Oleuropeinhydrolys is by lactic acid bacteria in natural green olives. LWT-Food Science and Technology, 78: 165-171.

Melliou, E., J. A. Zweigenbaum and A. E. Mitchell (2015). Ultrahigh-pressure liquid chromatography triple-quadrupole tandem mass spectrometry quantitation of polyphenols and secoiridoids in California-style black ripe olives and dry salt-cured olives. J. Agric. Food Chem., 63(9): 2400-2405.

Mojtaba, A., A. S. Mohammad and B. Mohsen (2015). Effect of the processing steps (harvesting time to pasteurization) on percentage of fatty acids in able olive. Curr. Nutr. Food Sci., 11: 44-52.

Romero, C., M. Brenes, K. Yousfi, P. Garcia and A. Garcia (2004). Polyphenol changes during fermentation of naturally Black olives. J. Agric. Food Chem., 52: 1973-1979.
Salas, J. J., J. Sanchez, U. S. Ramli, A. M. Manaf, M. Willians and J. L. Harwood (2000). Biochemistry of lipid metabolism in olive and other oil fruits. In: Prog. Lipid Res., 39: 151-180.

Sanchez, A. H., L. Rejano, A. Montano and A. De Castro (2001). Utilization at high $\mathrm{pH}$ of starter cultures of lactobacilli from Spanish style green olive fermentation. Intemational Journal of Food Microbiology, 67: 115-122.

Sánchez-Rodríguez, L., M. Mireia Corell, F. Hernández, E. Sendra, A. Moriana and A. A. CarbonellBarrachina (2019). Effect of Spanish-style processing on the quality attributes of HydroSOStainable green olives. J. Sci. Food Agric., 99: 1804-1811.

Servilli, M., L. Settanni, G. Veneziani, S. Esposto, O. Massitti and A. Taticchi (2006). The use of Lactobacillus pentosus $1 \mathrm{MO}$ to shorten the debittering process time of black table olives (cv. Itrana and Leccino): a pilotscale application. J. Agric. Food Chem., 54: 3869 3875.

Soler-rivas, C., J. C. Esp1 and H. J. Wichers (2000). Review oleuropein and related compounds. Journal of the Science of Food and Agriculture, 80(7): 1013-1023.

\section{تأثير عملية الغسيل بالماء المحضض أثثاء التصنيع على جودة زيتون المائدة الأخضر المصنع بالطريقة الأسباتية النية \\ سوزان محمود محمد عبد المجيد \\ قسم بحوث الزيوت و الدهون، معهذ بحوث تكنولوجيا الأغذية، مركز البحوث اعلئ الزر اعية، الجيزة، مصر}

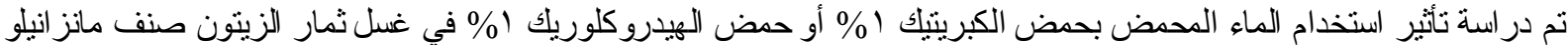

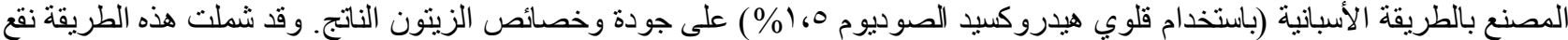

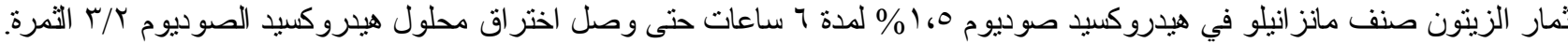

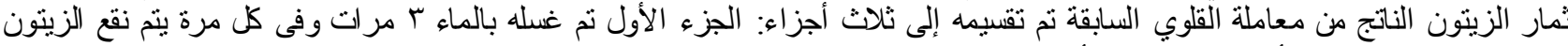

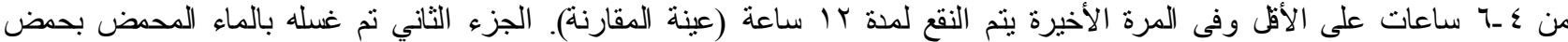

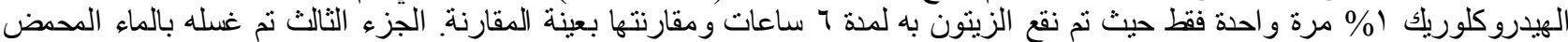

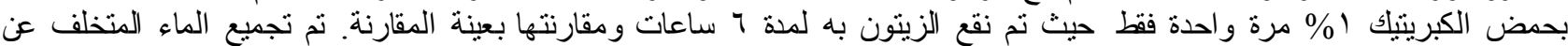

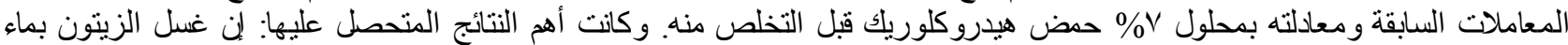

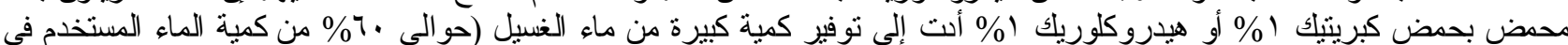

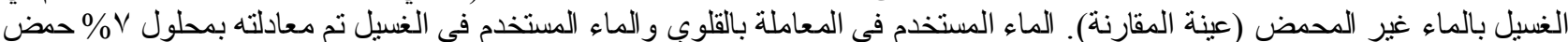

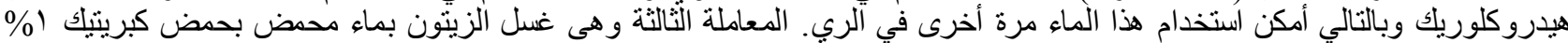

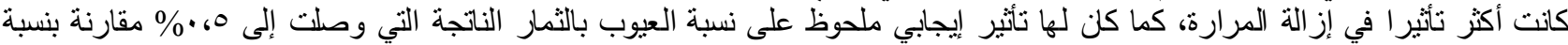

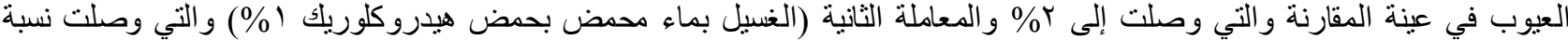
العيوب بها إلى 0، 1\% المثارنة 